REVISTA X, Curitiba, volume 14, n.3,275-291, 2019.

\title{
UMA EXPERIÊNCIA DE ENSINO DE LÍNGUA INGLESA POR MEIO DE UMA SEQUÊNCIA DIDÁTICA DO GÊNERO TEXTUAL BILHETE
}

An experience of English Language Teaching by means of a Didactic Sequence of note textual genre

\author{
Aline Maria VAZZATTA (UTFPR) ${ }^{1}$ \\ Dener Gabriel FERRARI (UTFPR) ${ }^{2}$ \\ Didiê Ana Ceni DENARDI (UTFPR) ${ }^{3}$
}

RESUMO: Neste artigo, discorremos sobre uma experiência de ensino de Língua Inglesa por meio de Sequência Didática realizada no âmbito do estágio curricular supervisionado do Curso de Licenciatura em Letras Português-Inglês da Universidade Tecnológica Federal do Paraná Pato Branco. Para tanto, realizamos uma revisão na literatura das concepções linguísticas que norteiam os documentos normativos do ensino básico, bem como do conceito de capacidades de linguagem e da metodologia da Sequência Didática, para, posteriormente, descrevermos e analisarmos nossas próprias aulas. Ao final deste texto, constatamos que a Sequência Didática está de acordo com as prescrições e orientações presentes nos documentos oficiais de ensino de línguas (materna e estrangeiras) e, também, é um procedimento metodológico extremamente útil aos professores de Língua Inglesa.

PALAVRAS CHAVE: Formação inicial de professores; Sequência Didática; Estágio Curricular Supervisionado.

ABSTRACT: In this paper, we talk about an experience of teaching English language by means of a Didactic Sequence carried out within the scope of the teaching supervised practice of Curso de Licenciatura em Letras Português-Inglês da Universidade Tecnológica Federal do Paraná campus Pato Branco. For that, we review linguistic conceptions with literature, which guide the normative documents of the Brazilian basic education, as well as the language capacities and the methodology of the Didactic Sequence, to later describe and analyze our own classes. At the end of this text, we verify that Didactic Sequence is coherent with the prescriptions and guidelines present in the official language teaching documents (mother and foreign languages) and also that it is an extremely useful methodological procedure to English language teachers.

KEY-WORDS: Pre-service teaching education; Didactic sequence; Teaching supervised practice.

\footnotetext{
${ }^{1}$ Graduanda em Letras - Português/Inglês pela Universidade Tecnológica Federal do Paraná. E-mail: alinemvazzatta@gmail.com.

${ }^{2}$ Graduando em Letras - Português/Inglês pela Universidade Tecnológica Federal do Paraná. E-mail: ferraridenergabriel@gmail.com.

${ }^{3}$ Doutora em Letras/Inglês pela Universidade Federal de Santa Catarina e professora do Programa de Pós-Graduação em Letras da Universidade Tecnológica Federal do Paraná. E-mail: didiedenardi@gmail.com.
} 
REVISTA X, Curitiba, volume 14, n.3,275-291, 2019.

\section{INTRODUÇÃO}

Considerando a atividade docente como práxis e decorrente da utilização da teoria e da prática em conjunto (PIMENTA, 1995), o estágio curricular se configura como uma "atividade teórica preparadora de práxis". Dessa forma, consideramos de grande importância investigar e refletir sobre o estágio curricular supervisionado, portanto obrigatório. Em nosso estágio aderimos à modalidade "estágio como investigação" (PIMENTA, 1995). Para tal, observamos aulas e realizamos a regência em uma turma de $9^{\circ}$ ano do Ensino Fundamental de uma escola pública urbana localizada na região sudoeste do Paraná, no ano de 2018.

Especificamente, a escola onde ocorreu a observação e a regência se localiza em uma região central da cidade e, em média, 32 alunos frequentavam o $9^{\circ}$ ano, divididos igualmente entre meninos e meninas de, em média, 14 anos. Ademais, a turma advinha de uma experiência pautada na abordagem de gramática e tradução (LEFFA, 1988) e não havia vivenciado até então nenhuma experiência sistemática com o ensino de escrita nas aulas de Língua Inglesa.

Assim sendo, este estudo caracteriza-se por ser de caráter qualitativointerpretativista em Linguística Aplicada (MOITA LOPES, 1994) e possui o objetivo de refletir acerca de uma experiência de ensino de língua inglesa implementada por meio de uma Sequência Didática do gênero de texto bilhete.

$\mathrm{O}$ presente texto está organizado em três seções, além desta introdução. Na primeira seção, revisamos as concepções linguísticas norteadoras dos documentos oficiais reguladores do ensino de Língua Inglesa, a saber, os Parâmetros Curriculares Nacionais (PCN - BRASIL, 1998), as Diretrizes Curriculares da Educação Básica do estado do Paraná (DCE - PARANÁ, 2008) e a Base Nacional Comum Curricular (BNCC - BRASIL, 2017).

Já na segunda seção, evidenciamos a importância das capacidades de linguagem (DOLZ; PASQUIER; BRONCKART, 2017) no âmbito da leitura e escrita, bem como apontamos a presença dessas capacidades dentro da Sequência Didática (DOLZ; NOVERRAZ; SCHNEUWLY, 2004). Na terceira seção, descrevemos a aplicação de nossa Sequência Didática (SD) e a analisamos com base nos pressupostos teóricos do Interacionismo Sociodiscursivo, para repensarmos nossa prática docente enquanto futuros professores de Língua Inglesa. Por fim, tecemos algumas considerações a respeito do trabalho realizado. 
REVISTA X, Curitiba, volume 14, n.3,275-291, 2019.

\section{OS DOCUMENTOS NORTEADORES DO ENSINO DE LÍNGUA INGLESA}

Antes de tratar dos documentos norteadores de ensino de Língua Inglesa, é importante mencionar, mesmo que de forma breve, que a situação do ensino de Línguas Estrangeiras no final do século XX no Brasil era, no mínimo, alarmante. A disciplina muitas vezes não era considerada como parte do currículo escolar, e não raro era relegada ao contraturno, em salas especiais com matrícula facultativa. Contudo, em 1996, mudanças significativas ocorreram por meio da Lei de Diretrizes e Bases da Educação Nacional (LDBEN 9394/96 - BRASIL, 1996), uma vez que esta traz determinações que modificaram o estatuto da disciplina no currículo.

A LDBEN (BRASIL, 1996) foi publicada como uma obrigatoriedade estabelecida na Constituição Federal de 1988, que previa a necessidade da educação se adequar às mudanças da Constituição. A partir de então, a disciplina língua estrangeira se torna obrigatória, como podemos ler a seguir: "Na parte diversificada do currículo será incluído, obrigatoriamente, a partir da quinta série, o ensino de pelo menos uma língua estrangeira moderna, cuja escolha ficará a cargo da comunidade escolar, dentro das possibilidades da instituição”. (BRASIL, 1996, Art. 26, § 5. )

Com a atualização da LDBEN de 2017 (Lei 13.415), novas mudanças ocorrem com essa disciplina curricular, tanto no ensino fundamental quanto médio. No primeiro fica estabelecido que a partir do sexto ano a língua inglesa deve ser ofertada. No segundo, a inclusão da língua inglesa se torna obrigatória, conforme citação: “Os currículos do ensino médio incluirão, obrigatoriamente, o estudo da língua inglesa e poderão ofertar outras línguas estrangeiras, em caráter optativo, preferencialmente o espanhol, de acordo com a disponibilidade de oferta, locais e horários definidos pelos sistemas de ensino". (BRASIL, 1996, Art. 35A, § 4. ${ }^{\circ}$ )

Com relação aos conteúdos de ensino da Educação Básica, fica estabelecido na LDBEN (BRASIL, 1996, Cap. IV, art. 9º, inciso IV), a construção de documentos orientadores e de diretrizes curriculares pela união, estados e municípios, dando origem à publicação de outros documentos de ensino, como os Parâmetros Curriculares Nacionais (PCN - BRASIL, 1998), Diretrizes Curriculares Estaduais (DCE PARANÁ, 2008), e mais recentemente a Base Nacional Curricular Comum (BNCC BRASIL, 2016). A seguir, procuraremos contextualizar os documentos supracitados.

Os PCN foram construídos após uma ampla discussão entre muitos profissionais da educação em todo o país, com o objetivo de promover mudanças positivas no sistema 
REVISTA X, Curitiba, volume 14, n.3,275-291, 2019.

educacional brasileiro. Ademais, esse documento normativo, busca

\begin{abstract}
por um lado, respeitar diversidades regionais, culturais, políticas existentes no país e, de outro, considerar a necessidade de construir referências nacionais comuns ao processo educativo em todas as regiões brasileiras. Com isso, pretende-se criar condições, nas escolas, que permitam aos nossos jovens ter acesso ao conjunto de conhecimentos socialmente elaborados e reconhecidos como necessários ao exercício da cidadania (BRASIL, 1998, p. $5)$.
\end{abstract}

Com relação à metodologia de ensino anterior aos PCN, tinha-se a predominância da Abordagem Comunicativa e também de exercícios que primavam pelo ensino de estruturas gramaticais e práticas de tradução (BRASIL, 1998). Dessa forma, os Parâmetros Curriculares Nacionais para o ensino de Língua Estrangeira (PCN LEM - BRASIL, 1998) buscavam alterar essa situação, apontando para uma nova maneira de compreender a linguagem, isto é, entender a linguagem como fenômeno social e como mediadora da interação entre o falante e o mundo, adotando-se assim uma perspectiva sociointeracionista de língua, baseada nos estudos de Bakhtin (2003). Com relação ao desenvolvimento/ensino-aprendizagem de língua inglesa, adota-se a mesma perspectiva, agora baseada nos estudos de Vigotski (1994; 2005) e seguidores que entendem que o desenvolvimento/aprendizagem do aluno ocorre por meio da linguagem nas interações sociais.

Ademais, é interessante destacar que o documento (BRASIL, 1998) deixa claro que a aprendizagem de uma língua estrangeira não se dá apenas pelo fato da aquisição de um novo código (viés utilitário e mercadológico), mas sim que o aprendizado de uma língua estrangeira auxilia o aluno a também compreender melhor a sua própria língua e cultura, bem como a natureza sociointeracional da linguagem.

Com relação ao processo de ensino-aprendizagem, os PCN recomendam que se deve partir de temas transversais e que é a partir da reflexão propiciada por esses temas que o ensino de cunho mais propriamente linguístico deve ser realizado. Assim, a sala de Língua Estrangeira é também vista pelo documento como local primordial de promoção da cidadania, em uma abordagem próxima à abordagem de letramento crítico $^{4}$, como defendida por Jordão e Fogaça (2007).

Considerando as determinações da LDBEN (BRASIL, 1996), nos anos iniciais

\footnotetext{
${ }^{4}$ O letramento crítico é entendido como uma perspectiva de ensino-aprendizagem de línguas, que concebe a língua como discurso e o texto como unidade de sentido verbal e não verbal, "enfatizando o processo de construção coletiva de sentidos" (JORDÃO; FOGAÇA, 2007, p.80). Ademais, o letramento crítico utiliza-se de diferentes gêneros textuais, "possibilitando ao aluno ter acesso a uma diversidade de textos e contextos de uso da linguagem" (p.80), consequentemente apto a entender o mundo que o cerca (JORDÃO; FOGAÇA, 2007).
} 
REVISTA X, Curitiba, volume 14, n.3,275-291, 2019.

do século XXI são construídas Diretrizes Curriculares Estaduais das disciplinas ministradas na Educação Básica nos diferentes estados da Federação Brasileira. No Paraná, o trabalho de construção das DCE teve início em 2003 e foi promovido pela Secretária do Estado de Educação, envolvendo professores da rede estadual de ensino em ampla discussão sobre teoria e prática de ensino de suas disciplinas, na leitura de versões preliminares do documento e na produção de pareceres. De modo geral, tais atividades ocorreram nas semanas pedagógicas a cada semestre com objetivo de assegurar a formação continuada dos professores. Sua publicação ocorreu em 2008 e desde então o ensino das diferentes disciplinas nas escolas estaduais do Paraná são orientados por esse documento.

As DCE de Línguas Estrangeiras Modernas (DCE LEM) do Paraná orientam-se pelo viés da pedagogia crítica e pelos estudos de Bakhtin e de seu Círculo. O documento propõe que o conteúdo estruturante da disciplina de Língua Estrangeira Moderna seja o discurso como prática social, ou seja, pretende superar o ensino utilitarista da língua e também compreender criticamente como ocorrem as relações da língua "com a cultura, o sujeito e a identidade" (PARANÁ, 2008, p. 55).

A partir desses pressupostos teóricos, as DCE afirmam que "[a] língua será tratada de forma dinâmica, por meio de leitura, de oralidade e de escrita que são as práticas que efetivam o discurso" (PARANÁ, 2008, p. 61). Assim, a unidade de ensino é o texto, pertencente aos mais variados gêneros e a partir dele é que "serão trabalhadas questões linguísticas, sociopragmáticas, culturais e discursivas, bem como as práticas do uso da língua: leitura, oralidade e escrita” (PARANÁ, 2008, p. 63).

Vale lembrar que na proposta de ensino expressa nas DCE LEM, não se pretende abolir as aulas de gramática, mas sim trazê-las para um ensino contextualizado, partindo sempre do texto e satisfazendo as questões linguísticas do aluno.

Por fim, a BNCC (BRASIL, 2016) é um documento que traz novas orientações, visando guiar a educação básica.

Conforme definido nas Diretrizes e Bases da Educação (Lei 9.394, 1996), a Base deve nortear os currículos dos sistemas e redes de ensino nas Unidades Federativas, como também as propostas pedagógicas de todas as escolas públicas e privadas de Educação Infantil, Ensino Fundamental e Ensino Médio, de todo o Brasil.

A Base estabelece conhecimento, competências e habilidades que se espera que todos os estudantes desenvolvam ao longo da educação básica. Orientada por princípios éticos, políticos e estéticos traçados pelas Diretrizes Curriculares Nacionais de Educação Básica, a Base soma-se aos propósitos 
REVISTA X, Curitiba, volume 14, n.3,275-291, 2019.

que direcionam a educação brasileira para a formação humana integral e a construção de uma sociedade justa, democrática e inclusiva (BRASIL, 2016).

Conforme a citação acima, a BNCC objetiva reunir um conjunto de conhecimentos, competências e habilidades que seja comum a todos os estudantes de todas as partes do país nos diferentes níveis de ensino de Educação Básica: infantil, fundamental e médio, avançando e dando continuidade aos preceitos já estabelecidos nos documentos oficiais anteriores a ela.

Com relação à Língua Inglesa, a BNCC a diz compulsória no Ensino Fundamental e Médio e busca desenvolver as noções mais atuais atreladas ao seu ensino, trazendo para isso alguns conceitos chave que guiam os eixos organizadores, tais como: caráter formativo de aprendizagem, multiletramentos e língua inglesa como língua franca (GIMENEZ, 2006; GIMENEZ et al., 2011).

Primeiramente, o caráter formativo de aprendizagem da língua inglesa faz pensar justamente na sua capacidade de comunicação com falantes não-nativos do inglês. Considera-se, então, o caráter formativo o responsável por mostrar aos alunos que o inglês é uma língua sem fronteira e território, ou seja, uma língua franca. Ademais, esse aspecto evidencia a necessidade de se aprender inglês não somente para ter acesso à língua do outro, mas também pela intelectualidade. Ao dominar o inglês, as pessoas garantem acesso a uma série de conhecimentos importantes para a constituição de saberes significativos.

Segundamente, tem-se o conceito de multiletramentos. Muitos autores (ROJO; MOURA, 2012, dentre outros) vêm discutindo este conceito, uma vez que nossos alunos estão envolvidos com aparelhos de multimídias que proporcionam aprendizado e, consequentemente, reproduzem o inglês por meio de linguagens distintas (jogos eletrônicos, filmes, séries, entre tantos outros) entre si. Além disso, consideramos as diferentes semioses, isto é, as diferentes produções de significado que são propiciadas por essas variadas linguagens.

Finalmente, apresentam-se as abordagens de ensino de língua inglesa enquanto língua franca (GIMENEZ, 2006; GIMENEZ et al., 2011). Este conceito é muito importante no que se refere à quebra de uma crença elitista de uso do inglês. Melhor dizendo, deve-se mostrar ao aluno que existem diferentes formas de uso do inglês para diferentes sujeitos e regiões. O reconhecimento da identidade do falante não-nativo é essencial para que as outras línguas e sotaques sejam valorizados igualmente.

Outrossim, são incluídos os eixos organizadores que estão ligados propriamente 
REVISTA X, Curitiba, volume 14, n.3,275-291, 2019.

à estrutura dos conteúdos. Temos, então, os eixos oralidade, leitura, escrita, conhecimentos linguísticos e dimensão intercultural. Cabe lembrar que, apesar de serem eixos diferentes, o esperado é que eles estejam engajados entre si, de maneira que os alunos desenvolvam todas as habilidades atribuídas à aprendizagem de uma língua.

Resumidamente, o eixo oralidade compreende a fala e a audição. O eixo leitura está atrelado à interpretação de textos em língua inglesa e compreensão de estruturas da língua em um formato maior que a frase. O eixo escrita prevê o conhecimento e aplicação das estruturas apreendidas através da leitura, assim como induz o aluno a produzir um texto de forma processual em busca de alcançar os objetivos esperados para a produção. $\mathrm{O}$ eixo conhecimentos linguísticos está ligado à gramática da língua inglesa que, por sua vez, deverá ser trabalhada de maneira contextualizada, apreensível para o aluno, por exemplo, a partir do gênero textual estudado, em nosso caso, o bilhete. Por fim, tem-se o eixo dimensão intercultural que concerne à cultura e que vai revelar aos alunos os diferentes sujeitos e ambientes que se relacionam com a língua inglesa.

Além dos eixos, são enfatizadas as competências para o ensino fundamental. As competências, de maneira geral, visam a inserção social em vários aspectos. Desde a necessidade de se conhecer as diferentes mídias atuais até a identificação das diferenças entre as línguas (materna e estrangeira) e a cultura da língua-alvo.

Ressalta-se, mais uma vez, que apesar do documento dividir as habilidades previstas para o ensino fundamental em eixos, todas estas habilidades estão interligadas nas práticas. Isto é, ao ler um texto, o leitor está adquirindo cultura, assim como quando escreve utiliza seu conhecimento gramatical da língua.

Ressalta-se, também, que as orientações sugeridas pelos documentos oficiais têm propiciado aos professores a elaboração de aulas de línguas estrangeiras mais significativas, que propiciam aos alunos um espaço onde seus conhecimentos de mundo são acolhidos e respeitados. Dessa forma, considera-se os documentos oficiais como suporte teórico importante para os professores de Línguas Estrangeiras, uma vez que, ao estudá-los, se apropriam de conhecimento aprofundado de ensino-aprendizagem de línguas. Uma das formas de trabalhar o texto oral, escrito e/ou multisemiótico é por meio do dispositivo didático sequência didática, que discutimos a seguir.

\section{SEQUÊNCIA DIDÁTICA E CAPACIDADES DE LINGUAGEM}

Considerando o que os documentos oficiais de ensino dizem, ou seja, assumindo 
REVISTA X, Curitiba, volume 14, n.3,275-291, 2019.

que o ensino de línguas deve ter por seu núcleo o texto, abordamos, nesta seção, a metodologia da SD. Uma SD prevê um ensino sistematizado da língua estudada a partir da abordagem de gêneros textuais orais e escritos e se materializa em uma sequência de atividades (DOLZ; NOVERRAZ; SCHNEUWLY, 2004). Em uma primeira etapa, são apresentados ao aluno vários textos de um mesmo gênero e é realizada, conjuntamente, a identificação das características de determinado gênero. Na segunda etapa, é pedido ao aluno que realize uma produção inicial de texto, que servirá como diagnóstico para o professor conhecer as capacidades de linguagem ${ }^{5}$ dos seus alunos, ou seja, conhecer as habilidades desses ligadas ao ato da escrita e leitura (DOLZ; PASQUIER; BRONCKART, 2017). A partir dessa primeira produção é que o terceiro passo é desenvolvido. Nesse momento, o professor deve desenvolver suas aulas, agrupando-as em módulos que visam melhorar o desempenho dos alunos em algum ponto contextual, textual e/ou gramatical, relacionados às capacidades de linguagem. Na quarta e última etapa, o texto é reescrito na produção final ${ }^{6}$. Dessa forma, defende-se um ensino no qual os alunos dominem os mais variados gêneros textuais, desenvolvendo criticidade e cidadania.

Retomando as capacidades de linguagem, tratam-se de habilidades/ conhecimentos necessários para que o aluno realize o ato de ler e produzir um texto de forma efetiva. No ato da leitura algumas questões são levantadas para que haja maior entendimento acerca do texto e também maior entendimento sobre seu papel na sociedade. Já com relação ao ato de produzir um texto, logo, um enunciado, dialoga com aquilo que Bakhtin (2003) identifica como natureza responsiva do enunciado:

Toda compreensão da fala viva, do enunciado vivo é de natureza ativamente responsiva (embora o grau desse ativismo seja bastante diverso); toda compreensão é prenhe de resposta, e nessa ou naquela forma a gera obrigatoriamente: o ouvinte se torna falante. A compreensão passiva do significado do discurso ouvido é apenas um momento abstrato da compreensão ativamente responsiva real e plena, que se atualiza na subsequente resposta em voz real alta (2003, p. 271).

A leitura e escrita de um texto pressupõem, portanto, uma ação referente a ele, podendo ser uma resposta a um texto lido, que se traduz ao assentir ou desaprovar algo, assim como pode se tratar de um novo texto que responda à determinada tese

\footnotetext{
${ }^{5}$ Uma discussão mais detalhada sobre capacidades de linguagem será feita ainda nesta seção.

6 A cada módulo, o professor pode solicitar uma reescrita ou readequação do texto, no entanto a quantidade é variável e determinada pelo professor. O mais importante é que o aluno venha a desenvolver, durante o processo, as capacidades de linguagem necessárias a uma boa produção do gênero de texto.
} 
REVISTA X, Curitiba, volume 14, n.3,275-291, 2019.

estabelecida. A partir dessa noção, reconhece-se o dialogismo da linguagem, onde os enunciados não são apenas produzidos, mas são, em essência, a resposta a outros enunciados já feitos e antecipações a outros que virão (BAKHTIN, 2003, p. 301).

Nessa lógica, podemos dizer que as capacidades de linguagem atuam. Assim como há a natureza responsiva do enunciado, existe uma série de considerações que as capacidades articulam sobre o enunciado. Se um enunciado responde outros, se identificando ou não com aquilo que já foi enunciado, características como o autor, objetivos, local de produção de um texto são essenciais para que o leitor ou o autor de um novo texto crie seu enunciado-resposta.

As capacidades de linguagem, para fins didáticos, são divididas em três: capacidade de ação, capacidade discursiva e capacidade linguístico-discursiva. Cada uma delas concentra em si um dos aspectos que um texto nos oferece e são essenciais na análise dos mais variados gêneros textuais em sala de aula.

A capacidade de ação refere-se aos aspectos relativos à situação de produção do texto. Isto inclui questões como autoria, objetivo da produção, local e data da produção, conteúdo geral do texto (DOLZ; PASQUIER; BRONCKART, 2017).

Já a capacidade discursiva centraliza a questão estrutural, organizacional de um texto, por isso entende-se pela capacidade de identificar o gênero e também os tipos de sequências textuais, para saber se se trata de uma sequência narrativa, descritiva, argumentativa, injuntiva, dialogal ou explicativa (DOLZ; PASQUIER; BRONCKART, 2017).

Há, ainda, a capacidade linguístico-discursiva, referente à análise das estruturas linguísticas (léxico, sintaxe, semântica) de um texto de acordo com seu contexto de produção, considerando o gênero textual (DOLZ; PASQUIER; BRONCKART, 2017).

Vale ressaltar, ainda, que Dolz, Pasquier e Bronckart (2017) consideram que as capacidades de linguagem estão emaranhadas, em constante interação umas com as outras. Finalmente, os autores teorizam que as capacidades de linguagem são objeto de aprendizagem social e reafirmam que a SD é a metodologia mais adequada para o ensino dessas capacidades no ambiente escolar.

Por fim, uma SD refere-se a uma metodologia de ensino que possui como principal objetivo "ajudar o aluno a dominar melhor um gênero de texto, permitindolhe, assim, escrever ou falar de uma maneira mais adequada numa dada situação de comunicação" (DOLZ; NOVERRAZ; SCHNEUWLY, 2004, p. 97). 
REVISTA X, Curitiba, volume 14, n.3,275-291, 2019.

Considerando o objetivo de uma SD, configuramos o nosso Estágio Curricular Supervisionado em Língua Inglesa no Ensino Fundamental nesse dispositivo metodológico com a utilização do gênero textual bilhete, como discutimos a seguir.

\section{RELATO E REFLEXÃO DAS AULAS}

A partir do referencial teórico apresentado, passamos à exposição e análise interpretativa das oito horas/aula ${ }^{7}$, destinadas à produção do gênero bilhete. Os quadros abaixo expostos sintetizam informações sobre as etapas da SD (da apresentação da situação inicial à produção final), sua temática, algumas informações referentes ao contexto de ensino e atividades realizadas.

Quadro 1: Apresentação da situação e produção inicial

\section{Contexto de ensino}

Temática: Relações afetivas

Público Alvo: alunos de $9^{\circ}$ ano de

Ensino Fundamental

Data: $27 / 09 / 2018$

Duração da aula: 50 minutos

\section{Atividades}

- Discussão sobre relações afetivas, com ênfase nos tipos de relações que desenvolvemos.

- Tomada de decisão pelos alunos sobre uma dessas suas relações.

- Produção escrita de um bilhete para uma pessoa conhecida dos alunos, com temas livres.

Fonte: dados da aula do dia 27/09/2018

A partir da primeira produção, foi possível diagnosticar o conhecimento dos alunos com relação ao gênero de texto "bilhete", uma vez que, de acordo com Dolz, Noverraz e Schneuwly (2004), a primeira produção é diagnóstica e também o ponto de partida do processo de avaliação.

Dessa forma, observamos que a grande maioria dos alunos não tinha conhecimento de elementos básicos do gênero bilhete, o que nos causou bastante surpresa, uma vez que se tratavam de alunos de $9^{\circ}$ ano e também de um gênero considerado primário (BAKHTIN, 2003). No entanto, é importante ressaltar que os alunos advinham de uma abordagem de gramática e tradução (LEFFA, 1988) e que até então jamais haviam realizado qualquer trabalho sistemático com escrita nas aulas de Língua Inglesa.

Por meio da produção-diagnóstica percebemos que os alunos tinham vários problemas com aspectos básicos de escrita de bilhetes, anotamos problemas de organização textual e sintaxe e suas respectivas descrições em diários de classe, e a

\footnotetext{
${ }^{7}$ Número de aulas exigido pelo regulamento do estágio obrigatório o curso de Letras da UTFPR campus Pato Branco.
} 
REVISTA X, Curitiba, volume 14, n.3,275-291, 2019.

partir do conhecimento do nível da turma, iniciamos o trabalho apontando para os aspectos do bilhete relacionados às capacidades discursivas, mostradas no Quadro 2 a seguir.

Quadro 2: Módulo 01

\begin{tabular}{|l|l|}
\hline \multicolumn{1}{|c|}{ Contexto de ensino } & \multicolumn{2}{|c|}{ Atividades } \\
\hline Temática: Relações afetivas & - Resolução de exercícios sobre a estrutura \\
Público Alvo: alunos de $\mathbf{9}^{\circ}$ ano de & composicional do gênero bilhete. \\
Ensino Fundamental & \\
Data: 04/10/2018 & \\
Duração da aula: 50 minutos &
\end{tabular}

Fonte: dados da aula do dia 04/10/2018

$\mathrm{Na}$ aula do dia 4 de outubro, apresentamos aos alunos exercícios de preenchimento de lacunas de partes do bilhete, tendo como objetivo fazer os alunos perceberem quais eram os elementos faltantes em suas primeiras produções do gênero bilhete. Em outras palavras, por meio de bilhetes de referência ${ }^{8}$, trabalhamos fortemente as capacidades discursivas, chamando a atenção para a organização do texto e para a importância dos elementos: data, destinatário, remetente, saudação e despedida; também abordamos as capacidades de ação, destacando as relações afetivas envolvidas entre destinatários e remetentes dos bilhetes de referência.

Nesse momento de exercícios, percebia-se mais uma vez a grande dificuldade dos alunos para compreender os textos em língua inglesa sem que tivessem de traduzir todas as palavras, procedimento típico da abordagem de ensino com a qual os alunos estavam acostumados. Muitos respondiam que não estavam entendendo, embora nos momentos de discussão oral em língua portuguesa todos compreendiam sobre o que estava sendo falado.

Quadro 3: Módulo 02

\begin{tabular}{l|l|}
\multicolumn{1}{|c|}{ Contexto de ensino } & \multicolumn{1}{|c|}{ Atividades } \\
\hline Temática: Relações afetivas & $\begin{array}{l}\text { - Reescrita dos bilhetes com uso de lista de } \\
\text { constatação. }\end{array}$ \\
Público Alvo: alunos de $\mathbf{9}^{\circ}$ ano de \\
Ensino Fundamental \\
Data: 04/10/2018 \\
Duração da aula: 50 minutos
\end{tabular}

Fonte: dados da aula do dia 04/10/2018

\footnotetext{
${ }^{8}$ De acordo com Dolz, Noverraz e Schneuwly (2004), o texto de referência é um texto real do gênero a ser trabalhado que se constitui como o principal guia para a produção do aluno.
} 
REVISTA X, Curitiba, volume 14, n.3,275-291, 2019.

Para a aula de reescrita dos bilhetes, usamos uma lista de constatação, em forma de perguntas, com elementos das capacidades discursivas estudados, como: há data no bilhete? há um destinatário? etc. Optamos por utilizar a lista de constatação, pois este é um mecanismo importante para que o aluno consiga se autocorrigir e também é um guia para as produções textuais, conforme argumentado por Denardi (2017). A pesquisadora ainda pontua que as listas de constatação podem ser construídas coletivamente em sala de aula, como um mecanismo dialético para a construção e a adequação dos textos. Porém, devido ao pequeno tempo de aplicação da Sequência Didática, a lista foi levada já pronta para a sala de aula.

Depois de destinar-se um tempo da aula para a explicação acerca da maneira como a lista deveria ser aplicada, reescrevemos um bilhete no quadro, mostrando para os alunos como eles deveriam proceder em seus próprios textos, buscando uma melhora significativa. A escrita coletiva é muito importante, pois nesse momento os alunos socializam seus conhecimentos e dúvidas, podendo aprender no coletivo, através das relações interpessoais (VIGOTSKI, 1994).

Naquele momento, buscava-se uma prática mais próxima aos alunos, de modo que todos eles dessem suas opiniões, mas também que se sentissem livres para perguntar sobre qualquer eventual dúvida relativa à estrutura composicional ou mesmo sobre questões referentes ao vocabulário, e, dessa forma, trabalhamos com as capacidades discursivas e linguístico-discursivas. No entanto, percebíamos que os alunos não respondiam muito bem a essa prática, pois a maioria se colocou em uma posição passiva de receptor.

Depois da reescrita coletiva, deixamos um espaço para que os alunos reescrevessem seus textos em duplas, podendo internalizar o conhecimento socializado anteriormente com toda a turma, ao mesmo tempo em que poderiam tirar suas dúvidas com o colega. Ou seja, pretendíamos que os alunos transformassem os conhecimentos interpessoais em intrapessoais (VIGOTSKI, 1994, p. 75). Durante esse período, passamos entre as carteiras e auxiliamos os alunos no que era preciso. Ao final da aula, recolhemos os textos e anexamos a nova versão dos alunos à versão anterior e à lista de constatação para que fosse possível observar a evolução/desenvolvimento dos alunos durante o processo da SD. Nas aulas seguintes, iniciamos o trabalho com as capacidades linguístico-discursivas, conforme Quadro 4 abaixo. 
Quadro 4: Módulo 03

\section{Contexto de ensino}

Temática: Relações afetivas

Público Alvo: alunos de $9^{\circ}$ ano de Ensino Fundamental

Data: 18/10/2018

Duração da aula: 50 minutos

\section{Atividades}

- Exercícios de gramática para:

a) revisão dos tempos verbais presente e passado do verbo to be;

b) revisão da second conditional.

Fonte: dados da aula do dia 18/10/2018

Conforme quadro 4 acima, na aula do dia 18 de outubro de 2018, abordamos a capacidade linguístico-discursivas, ou seja, os aspectos gramaticais que, de acordo com as observações dos textos produzidos ( $1^{\mathrm{a}}$ e $2^{\mathrm{a}}$ versões do bilhete), geraram muitas dúvidas nos alunos (verbo to be e o second contidional). A revisão do second conditional foi solicitada pelo professor regente da turma, uma vez que ele havia trabalhado este ponto gramatical anterior ao início de nosso estágio.

Para revisar os tempos verbais presente e passado simples do "to be", iniciamos por criar uma tabela, no quadro branco, contendo as conjugações do verbo to be nos tempos presente e passado. A tabela foi criada conjuntamente com os alunos, perguntávamos pelos pronomes e formas verbais e os alunos diziam ou nós mesmos tínhamos que dizer e completar a tabela. Na sequência, passamos alguns exercícios nos quais os alunos deveriam completar as lacunas de acordo com a conjugação adequada ao pronome pessoal e ao tempo verbal.

Detectamos sérios problemas no que diz respeito ao verbo to be e também ao que diz respeito à identificação do tempo verbal, pois mesmo depois de ser trabalhado isso em sala de aula, em alguns textos posteriores ainda apareceram problemas dessa estrutura. Além disso, os próprios livros didáticos trabalham esse tópico gramatical intensamente nos anos finais do Ensino Fundamental I. No entanto, identificamos que os alunos apenas decoram a maneira correta de preencher as lacunas e não conseguem aprender a utilizar a estrutura em um texto próprio, o que caracteriza mais um problema da abordagem que dá ênfase à gramatica e à tradução.

A mesma prática foi realizada com os exercícios relacionados ao second conditional. Passamos as orações para serem completadas como o second conditional no quadro e orientamos os alunos a completar as lacunas utilizando a tabela de verbos irregulares presentes no final dos livros didáticos. 
REVISTA X, Curitiba, volume 14, n.3,275-291, 2019.

Durante o período de realização de ambos os exercícios, buscamos amparar os alunos e sanar todas as suas dúvidas possíveis. Ambas as correções foram enfáticas e nesse momento procurávamos envolver todos os alunos nesse processo, embora geralmente apenas um número seleto de alunos se disponibilizasse a compartilhar suas respostas. O Quadro 5, a seguir, sintetiza o trabalho de produção final dos bilhetes.

Quadro 5: Produção final

\begin{tabular}{|c|c|}
\hline Contexto de Ensino & Atividades \\
\hline $\begin{array}{l}\text { Temática: Relações afetivas } \\
\text { Público Alvo: alunos de } 9^{\circ} \text { ano de } \\
\text { Ensino Fundamental } \\
\text { Data: } 25 / 10 / 2018 \\
\begin{array}{l}\text { Duração da aula: } 1 \text { hora e } 40 \\
\text { minutos }\end{array}\end{array}$ & $\begin{array}{l}\text { - Revisão da estrutura composicional do gênero de } \\
\text { texto "bilhete". } \\
\text { - Revisão da estrutura sintática dos tempos verbais do } \\
\text { to be } \\
\text { - Revisão da estrutura sintática da second } \\
\text { conditional. } \\
\text { - Devolutiva dos bilhetes aos alunos. } \\
\text { - Confecção de cartaz onde os alunos colocariam } \\
\text { seus bilhetes. } \\
\text { - Correção dosbilhetes pelos professores estagiários. } \\
\text { - Entrega dos bilhetes aos seus autores e entrega dos } \\
\text { bilhetes pelos autores aos seus destinatários. }\end{array}$ \\
\hline
\end{tabular}

Fonte: dados da aula do dia 25/10/2018

As duas últimas aulas ocorreram conjuntamente no dia 25 de outubro de 2018, havíamos planejado trabalhar novamente com a produção textual, reforçando ainda as questões relativas ao remetente e ao destinatário e ressaltando a importância da linguagem como uma prática social, ou seja, trabalhar as capacidades de ação. Contudo, esse trabalho foi feito de forma breve e articulado com uma maior atenção os pontos gramaticais, as capacidades linguístico-discursivas, uma vez que Dolz, Noverraz e Schneuwly (2004) argumentam que essa capacidade de linguagem deve ser trabalhada durante as últimas etapas da SD.

Assim, buscamos entregar os bilhetes dos alunos com pequenos comentários, de maneira que esses pequenos comentários, juntamente com a lista de constatação, pudessem auxiliar na produção final. Nessa reescrita, entregamos aos alunos também uma pequena folha de papel colorido para que eles escrevessem seus bilhetes e depois os entregassem para o destinatário escolhido, ou seja, um colega da turma.

Por fim, resta-nos destacar que, embora o trabalho com gêneros textuais seja difícil em uma turma que está acostumada com uma abordagem de ensino que priorize a 
REVISTA X, Curitiba, volume 14, n.3,275-291, 2019.

gramática e tradução, os resultados, em geral, foram positivos, uma vez que nenhum aluno se recusou a fazer as atividades propostas e que a grande maioria conseguiu desenvolver substancialmente as capacidades de ação e discursiva. Por outro lado, não é possível afirmar que todos os alunos conseguiram um desenvolvimento expressivo nas capacidades linguístico-discursivas, uma vez que o trabalho nessas capacidades demanda tempo maior.

\section{CONSIDERAÇÕES FINAIS}

Os documentos oficiais (PCN, DCE e BNCC) criados a partir do fim da década de 1990 surgem como uma tentativa de oficializar o ensino de língua estrangeira nas escolas do país. Desde lá, o que se entende por ensino de língua estrangeira vem mudando no país. A partir da criação dos $\mathrm{PCN}$, e seus respectivos temas transversais, o ensino passa a envolver questões de âmbito social. As DCE, já seguindo a teoria bakhtiniana, colocam o texto no centro do ensino, tornando o ato de aprender uma língua estrangeira como um ato de domínio social. A BNCC mantém a perspectiva interativista e inova ao trazer à discussão conceitos mais recentes, como é o caso dos multiletramentos e, no caso do inglês, inglês como língua franca.

Referente às capacidades de linguagem distribuídas na SD em torno do gênero bilhete, percebemos que o ensino baseado no texto e seus variados aspectos sociais permite que os alunos se vejam no mundo como protagonistas. Além disso, eles estão produzindo textos cientes da natureza responsiva dos enunciados, ou seja, atendendo às necessidades que cada gênero pede, para que assim essas produções criem elos com aquelas que já foram produzidas e sejam antecipações para as produções futuras. As capacidades de linguagem, juntamente com a natureza processual da SD, levam o aluno ao domínio de diversos gêneros textuais e, consequentemente, ao domínio de uma língua.

Ainda, inferimos que apesar do ensino processual elevar o nível de aprendizagem de línguas estrangeiras, é necessário que se adote essa forma de ensino de maneira integral, deixando de lado abordagens que priorizem unicamente a tradução ou a aquisição de tópicos gramaticais sem um contexto de aprendizagem que garanta ao aluno um conhecimento sólido. Compreende-se a gramática e a tradução como aspectos importantes para o processo de aprendizagem de uma língua, mas também se compreende que por esse caminho os alunos satisfazem unicamente às necessidades 
REVISTA X, Curitiba, volume 14, n.3,275-291, 2019.

imediatas do âmbito escolar, como provas e trabalhos, deixando - mais uma vez - de lado a aprendizagem totalizante de uma língua, o que inclui o conhecimento de sua cultura.

Por fim, podemos considerar que a experiência desenvolvida no estágio foi bastante significativa para nós, futuros professores de Língua Inglesa, uma vez que nos possibilitou a aplicação de uma metodologia em acordo com os documentos oficiais de ensino, ao mesmo tempo em que nos mostrou que nossa prática deve ser (re)pensada a todo o momento, visando experiências de aprendizagem mais significativas aos alunos.

\section{REFERÊNCIAS}

BAKHTIN, M.M. Estética da Criação Verbal. Introdução e tradução do russo por Paulo Bezerra; prefácio à edição francesa de Tzvetan Todorov. 4 ed. São Paulo: Martins Fontes, 2003.

BRASIL. Lei $N^{o}$ 9.394, de 20 de dezembro de 1996. Estabelece as diretrizes e bases da educação nacional, Brasília, DF, dez. 1996. Disponível em: <http://www.planalto.gov.br/ccivil_03/LEIS/L9394.htm>. Acessos em: mai. 2019.

BRASIL. Ministério da Educação. Secretaria da Educação Básica. Base nacional comum curricular. Brasília, DF, 2016. Disponível em: <http://basenacionalcomum.mec.gov.br/\#/site/inicio >. Acesso em: mai. 2018.

BRASIL. Secretaria de Educação Fundamental. Parâmetros curriculares nacionais: terceiro e quarto ciclos do ensino fundamental: língua estrangeira. Brasília: MEC/SEF, 1998.

DENARDI, D.A.C. Didatic Sequence: a dialetic mechanism for language teaching and learning. Revista Brasileira de Linguística Aplicada, Belo Horizonte, v. 17, n. 1, 2017.

DOLZ, J.; NOVERRAZ, M.; SCHNEUWLY, B.. Sequiências didáticas para o oral e a escrita: apresentação de um procedimento. In: SCHNEUWLY, B.; DOLZ, J. Gêneros orais e escritos na escola. Tradução de Roxane Rojo e Glaís Sales Cordeiro. Campinas, SP: Mercado das Letras, 2004, p. 95-128.

DOLZ, J., PASQUIER, E., BRONCKART, J.P. A Aquisição do discurso: a emergência de uma competência ou aprendizagem de diferentes capacidades de linguagem?. Tradução de Cassiano Ricardo Haag. Nonada Letras em Revista, Porto Alegre, v. 1, n. 28, p. 156-173, 2017.

GIMENEZ, T.N. et al. (org.). Inglês como língua franca: ensino aprendizagem e formação de professores. Campinas, SP: Pontes Editores, 2011.

GIMENEZ, T.N. English in a new world language order. In: MACHADO, L.T.; et al. (org.) Aspectos da linguagem: considerações teórico-práticas. Londrina: EDUEL, 2006, p. 59-72. 
JORDÃO, C.M.; FOGAÇA, F.C.. Ensino de inglês, letramento crítico e cidadania: um triângulo amoroso bem sucedido. Letras \& Línguas, Cascavel, v. 8, n. 14, p. 79-105, 2007.

LEFFA, V.J. Metodologia do ensino de línguas. In BOHN, H. I.; VANDRESEN, P. Tópicos em lingüística aplicada: $\mathrm{O}$ ensino de línguas estrangeiras. Florianópolis: Ed. da UFSC, 1988. p. 211-236.

MOITA LOPES, L.P. Pesquisa interpretativista em Linguística Aplicada: a linguagem como condição e solução. D.E.L.T.A., v. 10, n. 2, p. 329-338, 1994.

PARANÁ. Secretaria de Estado da Educação. Diretrizes Curriculares da Educação Básica - Língua Estrangeira Moderna. Curitiba: 2008.

PIMENTA, S.G. O Estágio na Formação de Professores: unidade teórica e prática? 2. ed. São Paulo: Cortez, 1995.

ROJO, R.; MOURA, E. (org.). Multiletramentos na escola. São Paulo: Parábola Editorial, 2012.

VIGOTSKI, L.S. A formação social da mente: o desenvolvimento dos processos psicológicos superiores. Tradução de José Cipolla Neto, et al. 5. ed. São Paulo: Martins Fontes, 1994.

VIGOTSKI, L.S. Pensamento e Linguagem. Tradução de Paulo Bezerra. São Paulo: Martins Fontes, 2005. 